\title{
Cognitive Diversity and Creativity: The Moderating Effect of Collaborative Climate
}

\author{
Raghda Abulsaoud Ahmed Younis ${ }^{1}$ \\ ${ }^{1}$ Department of Business Administration, Faculty of Commerce, Cairo University, Egypt \\ Correspondence: Raghda Abulsaoud Ahmed Younis, Department of Business Administration, Faculty of \\ Commerce, Cairo University, Egypt. E-mail: Raghdauniv@cu.edu.eg
}

Received: October 25, 2018

Accepted: November 30, 2018

Online Published: December 20, 2018

doi:10.5539/ijbm.v14n1p159

URL: https://doi.org/10.5539/ijbm.v14n1p159

\begin{abstract}
Creativity is the key for the organizational survival in challenges times. And diversity is one of the factors that could contribute to the creativity. There are many arguments about diversity-performance relationship. however, emphasizing if the cognitive diversity could enhance group creativity? And under which conditions? is still a research gap. The purpose of this research is to examine the cognitive diversity- creativity relationship in the work group. In addition, this research aims to examine the extent to which collaborative climate could reinforce this relationship. Data were collected from members working in financial institutions using a survey method. the results revealed the significance contributions of various collaborative climates in enhancing the diversity -creativity relationship.
\end{abstract}

Keywords: Diversity, cognitive, innovation, creativity, collaborative climate

\section{Introduction}

It is essential to understand how differing viewpoints affect individual, team and organizational performance. the concept Diversity was measured by different aspects within the literature review, such as surface-level diversity \& deep-level diversity. Accordingly, Previous Research has yielded inconsistent results about the relationship between diversity and performance (Miller, Burke, \& Glick, 1998). Hence, this study focuses on specific facet of diversity which is "Cognitive diversity. Cognitive diversity is a forum of diversity, which reflects the variation in beliefs (regarding cause-effect relationships) and variation in preferences (regarding individual, team and organizational goals) among members (Miller, 1990). In a team context; cognitive diversity could be defined as the degree to which team members differ in terms of experiences, and perspectives (Miller et al., 1998).

In general, There are two arguments in the relationship between diversity and performance. On one hand; diversity may enhance team outcomes \& performance (Horwitz \& Horwitz, 2007; Ely \& Thomas, 2001; Lu, Chen, Huang, \& Chien, 2015; Martins, Schilpzand, Kirkman, Ivanaj, \& Ivana, 2012). On the other hand, other scholars suggest that members prefer to work better with others similar to them. and thus, higher levels of diversity have no or less positive outcomes (Kochan, et al., 2003; Miller, 1990). Thus: understanding if cognitive diversity relates to the group creativity or not? In addition, how this relationship could be enhanced? is still unclear."

Scholars have asserted that the success or the failure of a work -team depends greatly upon the team's context or climate (Amabile, 1988; Somech \& Drach-Zahavy, 2013). Based on that, there is a need to explain what climate traits might help to tap the positive outcomes inherit in diversity? and what prevent negative effects associated with being different? Scholars revealed that cognitive diversity could have negative creativity outcomes due to communication, integration \& coordination impediments (Ness, 2017; Miller, 1990). As Ineffective coordination between group members will lead to increasing costs and negative outcomes. Hence, this paper argues that collaborative climate facilitates knowledge processing in a diverse team, and in turn fosters the team creativity.

\section{Theoretical Background}

\subsection{Cognitive Diversity and Creativity}

Based on the literature review; Diversity was examined by different perspectives i.e. surface and deep diversity. The surface or observable diversity is the diversity that can be easily recognized, such as demographic diversity. Sometimes, surface diversity can’t enhance creativity because of social conflicts possibility resulting from being 
different. On other hand, the deep or non-observable diversity, is the diversity that can't be easily recognized. usually relates to functional diversity and results from individual learning through a period. Such a diversity could promote creativity in the work place (e.g., information gathering and interpretation, combining different perspectives and building new ideas) by providing group members with a wide range of problem-solving methods, perspectives, ideas, knowledge, and believes (SHIN, KIM, LEE, \& BIAN, 2012), and thus team creativity (Somech \& Drach-Zahavy, 2013).

It is important to distinguish between perception and cognition. Perception related to how the individual capture the information needed for processing (Bromiley \& Rau, 2016). Otherwise, cognition means how individuals use the information (Anderson, 1990). Cognitive diversity results from a group that includes intelligent agents from various cognitive classes. It implies that the agents think differently and have different problem- solving methodologies (West \& Dellana, 2009). Cognitive diversity reflects diversity in terms of expertise, experiences, and perspectives (Miller et al., 1998).

Regarding the impact of cognitive diversity on performance ; it has been shown that cognitive diversity in work group can contribute to many positive outcomes, such as minimizing debiasing decision making (Meissner \& Wulf, 2017) and improving decision quality (Parayitam \& Papenhausen, 2016). An experimental research verified that decision errors decrease as the number of cognitive styles increase (West \& Dellana, 2009). which in turn, enhance creative formulations of responses ( Hambrick, Cho, \& Chen, 1996). and thus, the firm performance even within negative crises impacts ( Ooi, Hooy, \& Som, 2017).

Regarding the creativity; scholars revealed inconstant results about the diversity-creativity relationship. Some Researchers agree that heterogeneity in problem -solving approach is the key to any group potential creativity. since heterogeneity in terms of both idea generators (Innovators) and idea codifiers and organizers (Adapters) important for creativity ( Kurtzberg, 2005). Through the creativity process, members will have the benefit of getting a variety of information, thoughts and ideas because of the diversity in the functional backgrounds and educational backgrounds of other team members (Parayitam \& Papenhausen, 2016). Other scholars agreed that homogeneity is preferred for team performance; they describe the role of group cohesion for enhancing coordination and thus team outcomes (King \& Anderson, 1990). the associative theory and the information processing theory are used in this study in order to solve these contradictions.

According to the Associative theory (Mednick, 1962), the prospect of new ideas increased based on the association group members will have derived from the expressed thoughts and ideas of others ( Kurtzberg, 2005). Otherwise, according to the information processing theory; individuals exchange, process, evaluate, and interpret information from each other before arriving at solutions (Galbraith, 1973). Therefore, Teams have the advantages of gathering and processing a variety of information because of the diversity in the functional backgrounds, educational backgrounds, and cultural backgrounds embedded in the team (Parayitam \& Papenhausen, 2016). it seems that the cognitive diversity can foster creativity by increasing the chance of brainstorming and having a variety of ideas, perspectives, knowledge, values and cognitive resources regarding the problem-solving (Shin, et al., 2012; Horwitz \& Horwitz, 2007). with the abundant of cognitive resources; the individual -as a member in a team work- is likely to generate new ideas based on the way he/she exploits various thoughts and ideas of other team members to generate novel ideas (Somech \& Drach-Zahavy, 2013; Wang, Kim, \& Lee,2016). Accordingly, Scholars indicated that cognitive diversity is likely to enrich the knowledge pool and integration of different ideas from other members and thus creativity (Somech \& Drach-Zahavy, 2013; Parayitam \& Papenhausen, 2016; Wang, et al.,2016; Shin, et al.,2012).

Based on the above reasoning, Researches have shown that getting a variety in terms of functional background, education background, age, culture and knowledge is likely to have some positive effects on group creativity. For example, Wang, et al. (2016) revealed that cognitive diversity - team creativity relationship is significant, and the existence of member motivation and leadership is necessary. Another study by Shin, et al. (2012) emphasized the conditions under which cognitive diversity is likely to enhance creativity for individual team member among 68 teams from chines companies. the study revealed that leadership and creative self-efficiency moderate the relationship between cognition diversity and individual creativity. To sum up, we argue that to improve creativity in the work place, it is important to have an effective bundle of cognitive resources i.e. cognitive diversity.

$\mathrm{H} 1$ : cognitive diversity is positively impact overall group creativity.

\subsection{Cognitive Diversity, Collaborative Work Climate and Creativity}

Creativity is the production of novel and useful ideas regarding products, services, processes, and procedures by an individual, Groups of individual working together (Amabile, 1988; Shin, et al., 2012). These ideas may be completely new anywhere or new only to a focal group or organization (Shin, et al., 2012). Group creativity 
results from collective efforts to generate novel and useful ideas that can be implemented by the firm to improve its products, processes or context to gain a competitive advantage (Cirella, Radaelli \& Shani, 2014). Some Scholars adapt interpretive model of "Input-Mediators-Outcome-Input" (IMOVIE) within the team creativity context in order to understand the creativity complexity (Cirella, Radaelli, \& Shani, 2014). The model explains the creativity as the integration between (a) the micro - social system i.e. the individual and team - level inputs (such as the ability and incentive for members to be creative, diversity between team members, and team management style), and (b) the macro - social system i.e. the teams react to whether supporting or challenging the creative behaviors and outcomes (such as organizational and supervisory, encouragement, workgroup support and social capital). Based on that, we think that creativity is much depending on the work context that characterized by intensive knowledge and frequent collaborations.

Also, diversity is important for performance (Martins, et al., 2012), However, too much diversity could lead to conflicts resulting from disagreements (Finkelstein \& Hambrick, 1996; Miller, 1990) which, indeed, isn't beneficial for creativity (Jackson, Joshi, \& Erhardt, 2003). Organizations must find ways to manage differences among employees and prevent disrupting communication and cooperation impeding performance (Kearney, Gebert, \& Voelpel, 2009). However, if there isn't a sufficient way to process and share knowledge that was created, positive outcomes will not be achieved. Group members with different terminologies sometimes experienced problems communicating across different disciplines (Ness, 2017). This may cause un-ability to capture useful ideas need to achieve creativity. However, a differentiation - integration model was proposed by Staw, (2009) to solve these contradictions, in which diverse group could be held together in a coordinated structure to foster creativity within different stages i.e. idea creation and implementation. Accordingly, this paper proposed a model that facilitates creativity by incorporates the role of diversity and collaborations in the same model.

Some researchers used the Motivated information processing in groups theory to illustrate how the team can benefits from functional diversity. Such a diversity affords diverse pool of knowledge, skills, values and information. Therefore, by sharing and combining them, the likelihood to generate novel ideas increase (Cheung, Gong, Wang, Zhou, \& Shi, 2016). Other studies identify that sharing team members' expertise, knowledge, and skills, and knowledge integration can develop its creative potential stronger with higher cognitive team diversity (MEN, SWFONG, LUO, ZHONG, \& HUO, 2017). As we mentioned before; creativity is much depending on work environment (Amabile, Conti, Coon, Lazenby, \& Herron, 1996). It has been seen that a work climate that characterized by friendly atmosphere and positive interaction could relate to creativity ( Maimone \& Sinclair, 2015). At the organizational level - increasing connectivity and collaboration between multiple partners is beneficial to facilitate creativity climate and thus innovation (Yström, Aspenberg, \& Kumlin, 2015). At the group level, creativity is a result of individuals' interactions and access to knowledge in which the individual embedded (Soda, Stea, \& Pedersen, 2017). Interpersonal Communication with diverse associations within or external to the firm is expected to enhance creativity. Specially relationships that involve relatively infrequent interactions (Perry-Smith \& Shalley, 2003). Studies showed that leadership relates positively to group creativity through a climate that facilitates the interaction among team members. ex. exchange of knowledge and information (Zhang, Tsui, \& Wang, 2011). What is beneficial is the ability to capture useful ideas need to achieve creativity. actually, in order to capture these ideas, managers should be able to arise the hidden knowledge within the team work (Černe, Nerstad, \& Dys, 2014) ), And to facilitate social exchange relationships between team members i.e. collaboration facilitates knowledge, ideas sharing. therefore, the collaboration climate is a could be key vehicle for internal access to knowledge and thus innovation (Ahuja, 2000).

Collaboration is the ability to pull together and work closely and comfortably together to complete an interdependent task, pursue a mutual interest, or pursue a jointly held intriguing idea (Nemiro, 2015, p. 91). collaboration climate reflects the common perception of interpersonal collaborations in the work place. This climate positively relates to team members' creativity ( Zhu, Gardner, \& Chen, 2016). Collaborative climate is one of the major factors that influencing the effectiveness of knowledge process within team members (Sveiby \& Simons, 2002), and arising the hidden knowledge within the team (Černe, Nerstad, \& Dys, 2014). This climate can decrease the negative side of conflict process that intervein the cognitive diversity- team effectiveness relationship (Parayitam \& Papenhausen, 2016). It is characterized by sharing individual efforts, knowledge, and resources with other colleagues to achieve common goals (Zhu, Gardner, \& Chen, 2016).

In this study, we aim to examine different aspects of collaboration climate that was constructed by Sveiby \& Simons (2002), i.e. organizational, supervisor and colleague's collaboration. Most of the scholars discussed each level for collaboration climate separately (Yström, Aspenberg, \& Kumlin, 2015). For example; Amabile, et al. (1996) indicate that Collaborations between supervisor and subordinators are one of the factors that encourage 
creativity in the group. Or testing the role of overall collaborations. For example, Zhu et al. (2016) argued that collaborative overall has a positive and significant direct relationship with team members' creativity. Additionally, Cirella, et al. (2014) concluded that collaboration overall essential for developing team creativity and managers should develop a climate that facilitates coordination, collaboration and creativity. Also, a study by Nemiro (2015) explored the collaboration imbedded within team members, it revealed the key necessary dimensions for creativity climate of virtual teams. The study mentioned that cooperative and collaborative have been shown to be important for joint creative efforts, and that the more the Interdependency between team members the more need for collaboration, which in turn, led to higher creativity experiences. Based on the above discussion, we recognized that it's important to consider multidimensional view of collaboration when considering creativity in the work group. This view could add to the literature and the arguments of diversitycreativity relationship. Based on the above reasoning, we hypothesized the following:

$\mathrm{H} 2$ : collaborative climate moderates positively the relationship between cognitive diversity and group creativity. We proposed the following model that aims to examine the impact of cognitive diversity on group creativity. In addition, the model will examine the role of collaborative climates i.e. organizational culture supporting collaboration climate, immediate supervisor support collaboration, employee attitude toward collaboration and work group support in enhancing this relationship.

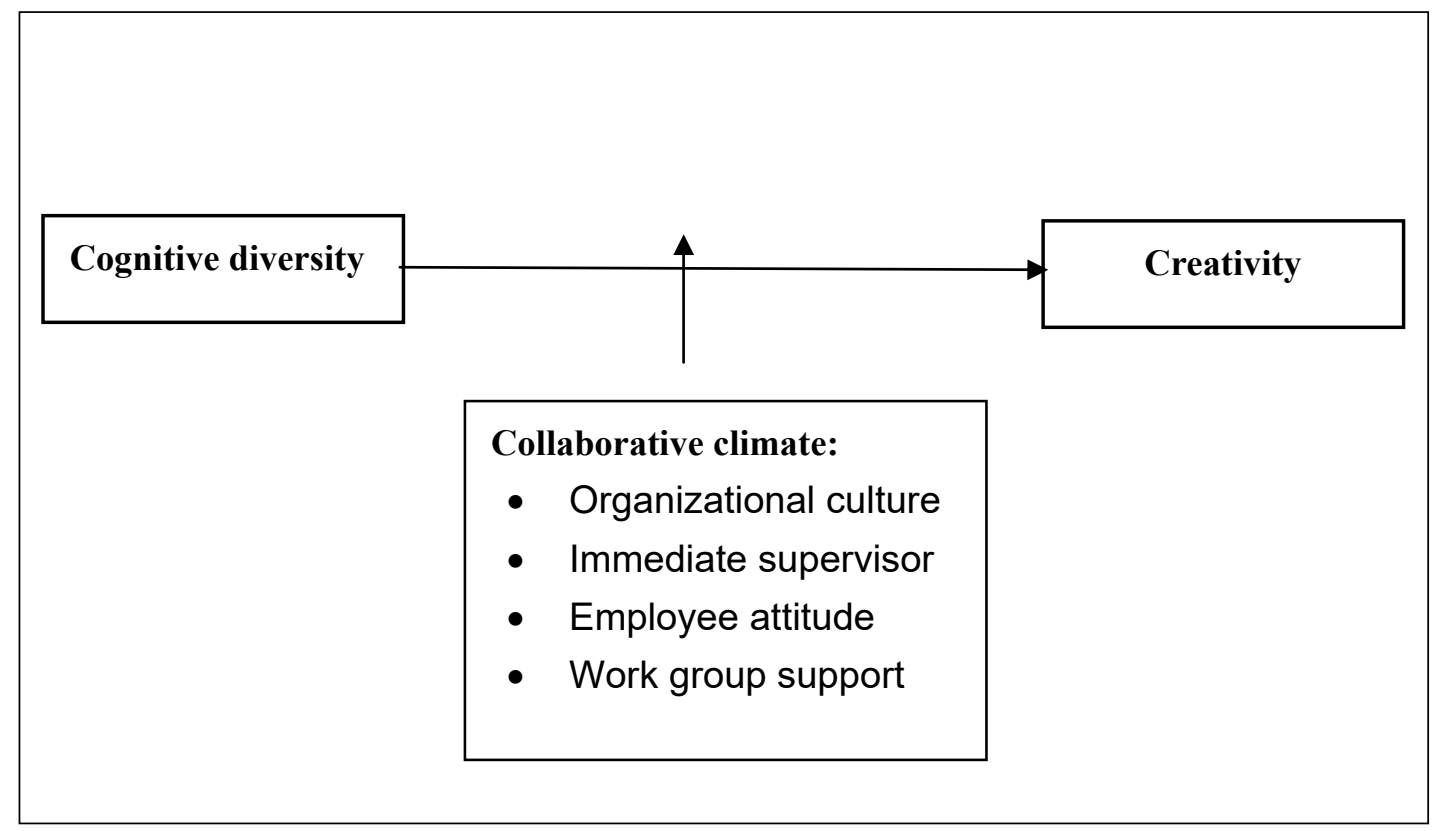

Figure 1. The Conceptual Research model

\section{Research Method}

A survey method used to collect our data from 378 members working in banks located in Great Cairo. Constructs operationalized with previously validated measures. members were asked to evaluate their group creativity overall performance, group cognitive diversity and collaborative climate. Regarding the group creativity; Perceptual measures predominantly used in the creativity measurement. According to Zhu \& Bao (2016), the subjective measure is more relevant than the objective measure in case of confidentiality of data and difficulties in obtaining micro- data. This study used Shin and Zhou's (2007) four-item scale, that assessing three aspects of creativity: newness of ideas, significance of ideas, and usefulness of ideas (Amabile, 1996). Cognitive diversity was measured using Van der Vegt \& Janssen (2003). The construct was measured by asking employees to report the extent to which they believe that the members of their group differ in thoughts, knowledge, and skills. and finally, collaborative climate was measured using Sveiby \& Simons (2002) multidimintional measure, which covers four aspects of collaborative climtes. Respondents were asked to indicate to what extent each statement described their work climate. Items were scored on five-point Likert scales ranging from 'Completely disagree' (1) to 'Completely agree' (5).

\section{Data Analysis and Results}

First; we conduct the descriptive and correlation analysis using the SPSS (V.18), then we conducted Amos (V.22) 
for the rest of our analysis. Table I shows the means, Standard deviations and correlations for all the variables that was examined in this study. Secondly; we build the measurement model in order to conduct the Confirmatory factor analysis (CFA).

Table 1. Means, Standard deviations and correlations

\begin{tabular}{|c|c|c|c|c|c|c|}
\hline \multicolumn{2}{|c|}{ Variables } & \multirow{2}{*}{$\begin{array}{l}\text { Mean } \\
2.7288\end{array}$} & \multirow{2}{*}{$\begin{array}{c}\begin{array}{c}\text { Standard } \\
\text { deviation }\end{array} \\
0.92913\end{array}$} & \multirow{2}{*}{$\begin{array}{l}1 \\
1.000\end{array}$} & \multirow[t]{2}{*}{2} & \multirow[t]{2}{*}{3} \\
\hline 1. & Diversity & & & & & \\
\hline 2. & C. climate & 3.4019 & 0.7449 & $0.566 * * *$ & 1.000 & \\
\hline 3. & Creativity & 3.3578 & 1.00176 & $0.597 * * *$ & $0.442 * * *$ & 1.000 \\
\hline
\end{tabular}

Notes. $\mathrm{N}=378$.

$* * * \mathrm{p}<.01$, (two-tailed tests).

We rely on two steps for building the measurement model: (a) loading the items to their relevant variables. In this step ; The four collaboration climates (organizational culture collaboration climate, immediate supervisor collaboration climate, work group support collaboration climate and employee attitude collaboration climate) were loaded on to one general variable (i.e. The collaborative climate). Regarding the diversity and creativity variables; the items were loaded respectively. (b) Building correlation between variables. Regarding this step; diversity, collaborative climates and creativity were correlated to build our measurement model. The estimated model showed a good model fit. Overall, the results were at the acceptance levels, supporting the validation of all constructs measured. CMIN/DF is below the accepted score 5, while GFI, CFI and TLI are close to score 1, which can indicate good model fit (Hair, Anderson, Babin, \& Black, 2010). Additionally, the loading for each for each individual item, incorporated into each of the constructs examined, is higher than the score 0.5.

Table 2. Overall model goodness of fit for the measurement model

\begin{tabular}{ll}
\hline Model fit index & SCORES \\
\hline Minimum sample discrepancy divided by degrees of freedom (CMIN/DF) & 2.892 \\
Goodness-of-fit index (GFI) & 0.840 \\
Comparative fit index (CFI) & 0.922 \\
Root Mean Square Error of Approximation (RMSEA) & 0.071 \\
Normed fit index (NFI) & 0.887 \\
Tucker-Lewis coefficient (TLI) & 0.911 \\
\hline
\end{tabular}

Confirmatory factor analysis (CFA) was conducted to test the construct validity of the measures. Using both SPSS and AMOS software, we evaluated the construct reliability by conducting composite reliability (CR). The results were at acceptance scores (Malhorta, 2010); CR for all construct $>0.9$ (Table III). Construct validity can be assessed through the estimation of each measure's convergent, discriminate validity and factor loading for each item. Construct, convergent, and discriminate validity were tested within several articles (e.g. Asiaei \& Jusoh, 2015).

For convergent validity, the average variance extracted (AVE) scores have their ranges between 0.699 and 0.848. In addition, Discriminate validity was tested by comparing the square root of the "average variance extracted" for each construct with the correlations with other constructs in the model (Fornell \& Larcker, 1981; Hair, et al., 2010). The results indicated that the scores of the square root of (AVE) have their ranges between 0.836 and 0.921. And the AVE score of each construct was higher than the correlations with the rest of the constructs, which support the discriminate validity for the constructs.

Table 3. Results of confirmatory factor analysis

\begin{tabular}{lllllll}
\hline & CR & AVE & MSV & Creativity & Diversity & C.climate \\
\hline Creativity & $\mathbf{0 . 9 0 3}$ & $\mathbf{0 . 7 0 0}$ & 0.426 & $\mathbf{0 . 8 3 6}$ & & \\
\hline Diversity & $\mathbf{0 . 9 0 3}$ & $\mathbf{0 . 6 9 9}$ & 0.426 & 0.653 & $\mathbf{0 . 8 3 6}$ & \\
\hline C. climate & $\mathbf{0 . 9 5 7}$ & $\mathbf{0 . 8 4 8}$ & 0.371 & 0.450 & 0.609 & $\mathbf{0 . 9 2 1}$ \\
\hline
\end{tabular}

Note. correlations are significant at $\mathrm{p}<0.001$; Italic bold: square root of AVE. 
To test our hypotheses; we build the structured equation model (SEM) using Amos (V.22).the first hypothesis proposed a positive significant relationship between cognitive diversity and perceived group creativity. The findings in Figure II show that cognitive diversity is positively relates to perceived group creativity ( $\mathrm{b}=0.45, p$ $<.001$ ). Our research results provide support for Hypothesis 1 . In addition, Hypothesis 2 proposed that overall collaborative climate will moderate the positive relationship between cognitive diversity and creativity, where the relationship is stronger when collaboration is higher. The analysis results in Figure II show that the interaction standardized coefficient for diversity and collaborative climate (i.e. the moderate variable) was significant $(b=0.11, p<0.05)$. A simple slope test was also conducted, revealing the effect of the moderation variable. Figure III plots the interaction using the stats tool package (Gaskin, 2016), which shows that the relationship between cognitive diversity and creativity is stronger when collaborative climate is high. these results support Hypothesis 2.

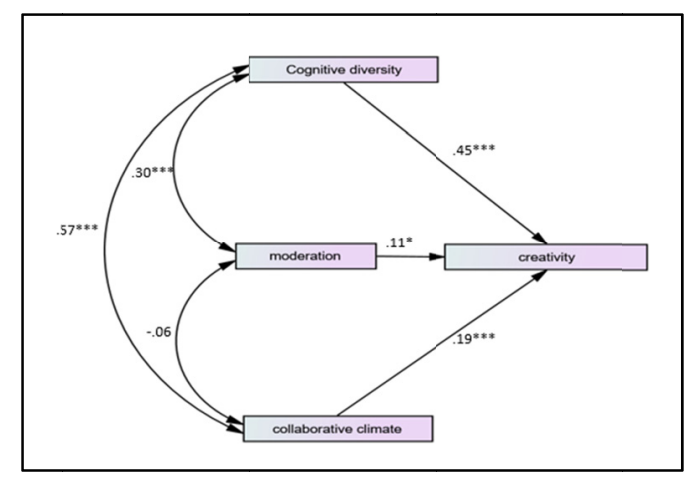

Figure 2. The research model results

Notes. ${ }^{* * *} \mathrm{p}<.01,{ }^{*} \mathrm{p}<0.5$, (two-tailed tests).

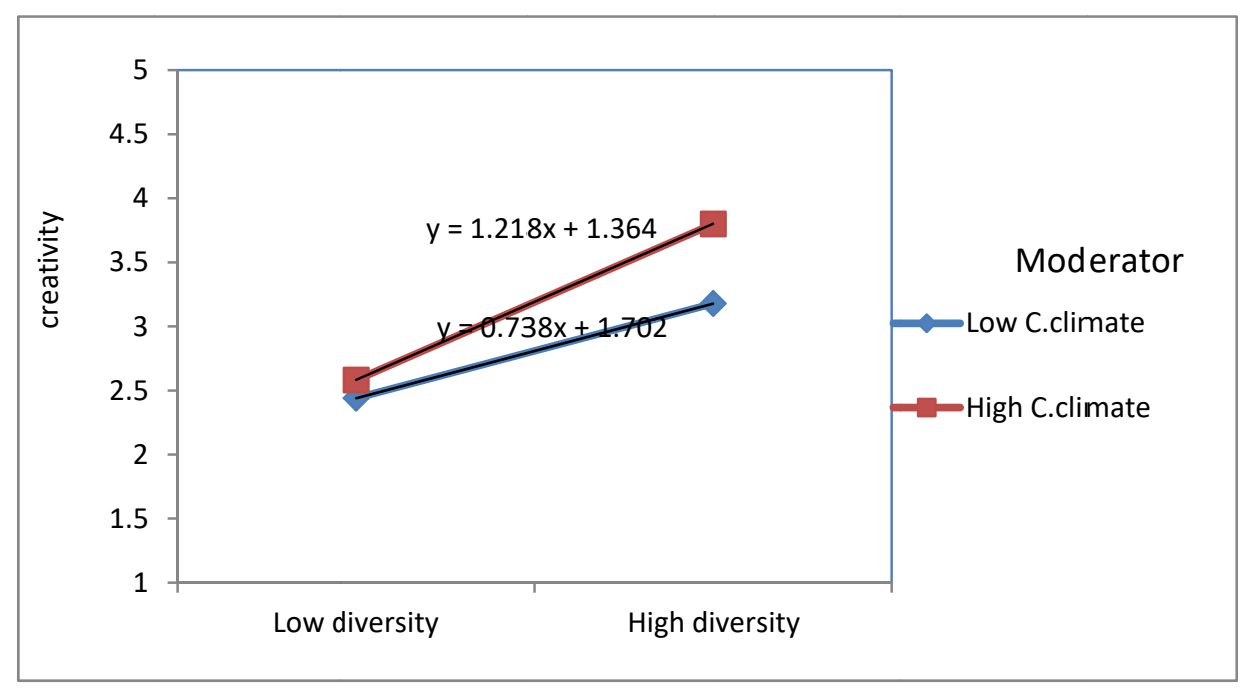

Figure 3. The moderation slope

Further a moderation analysis was conducted for each collaborative climate in order to estimate the most significant collaborative climate. The results in Table (V) revealed that the interaction coefficient for diversity and organizational culture collaborative climate wasn't significant $(b=0.058)$. whereas the rest of collaborative climates interactions i.e. the interaction coefficient for diversity and immediate supervisor support, the interaction coefficient for diversity and team support and, the interaction coefficient for diversity and employee attitude were significant $(\mathrm{b}=0.105, \mathrm{~b}=0.100, \mathrm{~b}=0.110, p<.0 .05)$ respectively. 
Table 5. The moderations tests for collaborative climates

\begin{tabular}{clll}
\hline & Diversity & Climate & Moderation interactions \\
\hline Model 1 & $0.488 * * *$ & $0.179^{*}$ & $0.058(\mathrm{n} . \mathrm{s})$ \\
Model 2 & $0.504 * * *$ & $0.110^{*}$ & $0.105^{*}$ \\
Model 3 & $0.472 * * *$ & $0.202 * * *$ & $0.100^{*}$ \\
Model 4 & $0.511 * * *$ & $0.128^{*}$ & $0.110^{*}$ \\
Notes. $* * * \mathrm{p}<.001, * \mathrm{p}<.05$. & & &
\end{tabular}

Model 1: organizational culture collaboration climate as a moderator, Model2: immediate supervisor collaboration climate as a moderator, Model 3: work group support collaboration climate as a moderator, Model 4: employee attitude collaboration climate as a moderator.

\section{Discussion}

Our research focused on specific aspect of diversity — cognitive diversity — and considered this aspect regarding group creativity. We focused on this particular diversity and its' outcome as it provided the opportunity to study the way in which employees experience the contradictions inherent in the way of thinking, resolving problems, decision making and ideas resulting from diversity. By drawing on the associative theory and the information processing theory. we offer insights into the creativity in the work group that have been highlighted as an important area for research and a critical key for organizational survival.

First, in regard to diversity, our study indicated that cognitive diversity was linked to positive outcomes. This finding is in line with some researches (Horwitz \& Horwitz, 2007; Ely \& Thomas, 2001; Lu, Chen, Huang, \& Chien, 2015; Martins, et al. 2012). However, it may disagree with other researches who revealed that homogeneity is preferred in the team construction, and that existence of diversity could lead to conflicts resulting from disagreements (Finkelstein \& Hambrick, 1996; Miller, 1990), explaining the role of group cohesion (King \& Anderson, 1990). It seems that cognitive diversity is a double-edged sword. Also, diversity is essential for creating ideas, however if the work group suffers from ambiguous, selfishness, conflicts or insecure feelings; it may result in negative outcomes. The study revealed also that the Collaborative climate was positively related to creativity in the work group, agreeing with prior researches (Zhu, et al., 2016; Nemiro, 2015). In addition, collaborative climate enhances / enriches the group creativity associated with the cognitive diversity.

Secondly, the findings suggest that it may be beneficial to draw on resource -based theory and to view cognitive diversity as intangible resources to understand how managers and employees may exploit various knowledge and experiences in a diverse group. With the abundant cognitive resources, the employees are likely to generate new ideas (Somech \& Drach-Zahavy, 2013; Wang, Kim, \& Lee, 2016) and thus group creativity (Parayitam \& Papenhausen, 2016; Wang, et al.,2016; Shin, et al.,2012). In our case organizations, Collaborative climate mechanisms appeared to act as a valuable resource in enhancing group performance. In the case of group creativity, our analysis revealed that high levels of overall collaborations (i.e. supervisor collaboration, team collaboration and individual attitude for collaboration) intensified the relationship between cognitive diversity and creativity.

Our findings strengthen arguments in the literature that, even if there are some negative aspects associated with being different, the group will be more likely creative when such collaborations and coordination's' mechanisms exist within different facets of work (i.e. Between the individual member and his/her supervisor or between the members themselves). While the research provides number of important insights- as any research - it has some limitations. First, this study is cross-sectional and is based on the survey tool to collect data from the employees. Second, we considered employees' perception when measuring group creativity. however, this was related to decreasing the bias level that could result when measuring the group performance with only one person i.e. the supervisor. Third, we examined only one aspect of diversity, future research might include other facets of diversities that could contribute positively to performance. Finally, the research was conducted within a specific field of study, and it would be useful to test the model across different sectors as a way for revealing generalizability of the results.

The findings suggest many issues to be considered. First; that the way the members, in a diverse group, interact and collaborate may enforce knowledge, thoughts and experiences exchange. Which in turn, foster new ideas development. In Second; it's required from the line manager to be aware of the potential consequences of diversity (the positive and negative ones). The decisions on group composition, regarding the team depth i.e. the variety of thoughts, perceptions, problem-solving terminologies and cognitive styles should be taken with 
cautious after careful analysis. Even in situations where a manager may have a limited control over the process of selecting individuals that they supervise, there is at least some scope to manage the variations in thoughts, believes and values that may exist in their team. Finally; this study suggests that investment in social networks and enhancing coordination and smoothly knowledge processing can reveal new ideas and thus creativity. This suggests that managers might consider effective ways in which both strengthen existing collaboration mechanisms and to explore new methods for collaborations (considering multidimensional view of collaboration climate). These new methods afford greater opportunities for employees to (a) capture new thoughts, knowledge, ideas and values. (b) accept others' thoughts and ideas, and (c) learn and combine different thoughts, information and ideas in order to develop new ones. It will then be the responsibility of the supervisors to assert that such opportunities are available for their employees.

\section{References}

Ahuja, G. (2000). Collaboration Networks, Structural Holes, and Innovation: A Longitudinal Study. Administrative Science Quarterly, 45(3), 425-455.

Amabile, T. (1988). a model of creativity and innovation in organization. Research in Organizational Behavior, 10, 123-167.

Amabile, T. M. (1996). Assessing the Work Environment for Creativity. The Academy of Management Journal, 39(5), 1154-1184.

Anderson, J. R. (1990). Cognitive psychology and its implications: A series of books in psychology. New York: Freeman/Times Books/Henry Holt \& Co.

Asiaei, K., \& Jusoh, R. (2015). A multidimensional view of intellectual capital: the impact on organizational Performance. Management Decision, 53(3), 668-697. http://dx.doi.org/10.1108/MD-05-2014-0300

Bromiley, P., \& Rau, D. (2016). Social, Behavioral, and Cognitive Influences on Upper Echelons During Strategy Process: A Literature Review. Journal of Management, 42(1), 174-202. https://doi.org/10.1177/0149206315617240

Černe, M., Nerstad,. C. G. L., \& Dys,. A. (2014). What Goes Around Comes Around: Knowledge Hiding, Perceived Motivational Climate, and Creativity. Academy of Management, 57(1), 172-192. http://doi.org/10.5465/amj.2012.0122

Cheung, S. Y. (2016). When and how does functional diversity influence team innovation? The mediating role of knowledge sharing and the moderation role of affect-based trust in a team. human relations, 69(7), 1507-1531. https://doi.org/10.1177/0018726715615684

Cirella, S., Radaelli, G., \& Shani, A. B. (2014). Team creativity: A complex adaptive perspective. Management Research Review, 37(7), 590-614. https://doi.org/10.1108/MRR-12-2012-0261

Ely, R. J., \& Thomas, D. A. (2001). Cultural Diversity at Work: The Effects of Diversity Perspectives on Work Group Processes and Outcomes. Administrative Science Quarterly, 46, 229-273.

Finkelstein, S., \& Hambrick, D. (1996). Strategic Leadership: Top Management Executives and their Effects on Organizations. MN: West, St Paul.

Fornell, C., \& Larcker, D. (1981). Evaluating structural equation models with unobservable variables and measurement error. Journal of Marketing Research, 18(1), 39-50.

Galbraith, J. (1973). Designing Complex Organizations. MA: Addison-Wesley.

Gaskin, J. (2016). Two way interactions.Stats Tools Package. Retrieved from http://statwiki.kolobkreations.com

Hair, J., Anderson, I., Babin, B., \& Black, W. (2010). Multivariate data analysis: A global perspective. Upper Saddle River, NJ: Pearson.

Hambrick, D. C., Cho, T. S., \& Chen, M. J. (1996). The Influence of Top Management Team Heterogeneity on Firms' Competitive Moves. Administrative Science Quarterly, 41(1), 659-684.

Horwitz, S. K., \& Horwitz, I. B. (2007). The Effects of Team Diversity on Team Outcomes: A Meta-Analytic Review of Team Demography. Journal of Management, 985-1015. https://doi.org/10.1177/0149206307308587

Jackson, S., Joshi, A., \& Erhardt, N. (2003). Recent Research on Team and Organizational Diversity: SWOT Analysis and Implications. Journal of Management, 29(6), 801-830. https://doi.org/10.1016/S0149-2063(03)00080-1 
Kearney, E., Gebert, D., \& Voelpel, S. C. (2009). When and how diversity benefits teams: The importance of team memberss' need for cognition.. Academy of Management Journal, 52(3), 581-598. https://doi.org/10.5465/amj.2009.41331431

King, N., \& Anderson, N. (1990). Innovation in working groups. Innovation and creativity at work, 81-100.

Kochan, T. (2003). The effects of diversity on bussiness performance:report of the diversity research network.. Human Resource Management, 42(1), 3-21. https://doi.org/10.1002/hrm.10061

Kurtzberg, T. R. (2005). Feeling Creative, Being Creative: An Empirical Study of Diversity and Creativity in Teams. Creativity Research Journal, 17(1), 51-65.

Lu, C. M., Chen, S. J., Huang, P. C., \& Chien, J. C. (2015). Effect of diversity on human resource management and organizational performance. Journal of Business Research, 68, 857-861. http://dx.doi.org/10.1016/j.jbusres.2014.11.041

Maimone, F., \& Sinclair, M. (2015). Affective climate, organizational creativity, and knowledge creation: case study of an automotive company. In Emotions and Organizational Dynamism, 309-332. https://doi.org/10.1108/S1746-9791(2010)0000006016

Malhorta, N. (2010). Markeing research : an applied orientation. N.J: Pearson.

Martins, L. L. (2012). A Contingency View of the Effects of Cognitive Diversity on Team Performance: The Moderating Roles of Team Psychological Safety and Relationship Conflict. Small Group Research, 44(2), 96-126. https://doi.org/10.1177/1046496412466921

Mednick, S. A. (1962). The associative basis of the creative process. psychological Review, 69(3), $220-232$.

Meissner, P., \& Wulf, T. (2017). the effect of cognitive diversity on the illusion of control bias in strategic decisions: An experimental investigation. European Management Journal, 35, 430-439. http://dx.doi.org/10.1016/j.emj.2016.12.004

MEN, C. (2017). When and how knowledge sharing benefits team creativity: The importance of cognitive team diversity. Journal of Management \& Organization, 1-18. https://doi.org/10.1017/jmo.2017.47

Miller, C. (1990). Cognitive diversity within management teams: Implications for strategic decision processes and organizational performance. s.1.:Un published doctoral disseration,Graduate School of Business, University of Texas..

Miller, C., Burke, L., \& Glick, W. (1998). Cognitive diversity among upper-echelon excutives: implications for strategic decision processes. Strategic Management Journal, 19, 39-58.

Nemiro, J. E. (2015). The climate for creativity in virtual teams. Advances in Interdisciplinary Studies of Work Teams, 79-114. https://doi.org/10.1016/S1572-0977(00)07007-2

Ooi, C., Hooy, C., \& Som, A. (2017). The influence of board diversity in human capital and social capital in crisis. Managerial Finance, 43(6), 700-7015. https:// doi.org/10.1108/MF-08-2016-0226

Parayitam, S., \& Papenhausen, C. (2016). Agreement-seeking behavior, trust, and cognitive diversity in strategic decision making teams: Process conflict as a moderator. Journal of Advances in Management Research, 13(3), 292-315. https://doi.org/10.1108/JAMR-10-2015-0072

Perry-Smith, J. E., \& Shalley,. C. E. (2003). The Social Side of Creativity: A Static and Dynamic Social Network Perspective. The Academy of Management Review, 28(1), 89-106. https://doi.org/10.1108/JAMR-10-2015-0072

Shin, S. J., \& Zhou, J. (2007). When Is Educational Specialization Heterogeneity Related to Creativity in Research and Development Teams? Transformational Leadership as a Moderator. Journal of Applied Psychology, 92(6), 1709-1721. https://doi.org/10.1037/0021-9010.92.6.1709

Shin, S. J., Kim, T. Y., Lee, J. Y., \& Bian, L. (2012). Cognitive team diversity and indvidual team members creativity: a cross-level interaction. Academy of Management Journal, 55(1), 197-212. http://dx.doi.org/10.5465/amj.2010.0270

Soda, G., Stea, D., \& Pedersen, T. (2017). Network Structure, Collaborative Context, and Individual Creativity. Journal of Management, 1-27. https://doi.org/10.1177/0149206317724509

Somech, A., \& Drach-Zahavy, A. (2013). Translating Team Creativity to Innovation Implementation: The Role of Team Composition and Climate for Innovation. Journal of Management, 39(3), 684-708. https://doi.org/10.1177/0149206310394187 
Staw, B. (2009). Is group creativity really an oxymoron?some thoughts on bridging the cohesion- creativiy divide.. Research on Managing Groups and Teams, 12, 311-323. https://doi.org/10.1108/S1534-0856(2009)0000012015

Sveiby, K., \& Simons, R. (2002). Collaborative climate and effectiveness of knowledge work - an empirical study. Journal of Knowledge Management, 6(5), 420-433. https://doi.org/10.1108/13673270210450388

Van der Vegt, G. S., \& Janssen, O. (2003). Joint Impact of Interdependence and Group Diversity on Innovation. Journal of Management, 29, 729-751. doi:10.1016/S0149-2063(03)00033-3

Wang, X. H., Kim, T. Y., \& Lee, D. R. (2016). Cognitive diversity and team creativity: Effects of team intrinsic motivation and transformational leadership. Journal of Business Research, 1-10. http://dx.doi.org/10.1016/j.jbusres.2016.02.026

West, D., \& Dellana, S. (2009). Diversity of ability and cognitive style for group decision processes. Information Sciences, 179, 542-558. https://doi.org/10.1016/j.ins.2008.10.028

Yström, A., Aspenberg, H., \& Kumlin, A. (2015). Exploring the creative climate in an open innovation arena : Identifying challenges and possibilities. European Journal of Innovation Management, 18(1), 70-85. https://doi.org/10.1108/EJIM-08-2013-0085

Zhang, A. Y., Tsui, A. S., \& Wang, D. X. (2011). Leadership behaviors and group creativity in Chinese organizations: The role of group processes. The Leadership Quarterly, 22, 851-862. https://doi.org/10.1016/j.leaqua.2011.07.007

Zhu, K., \& Bao, H. (2015). High-performance human resource management and firm performance. Industrial Management \& Data Systems, 115(2), 353-382, http://dx.doi.org/10.1108/IMDS-10-2014-0317

Zhu, Y. Q., Gardner, D. G., \& Chen, H. G. (2016). Relationships Between Work Team Climate, Individual Motivation, and Creativity. Journal of Management, 1-22. https://doi.org/10.1177/0149206316638161

\section{Copyrights}

Copyright for this article is retained by the author(s), with first publication rights granted to the journal.

This is an open-access article distributed under the terms and conditions of the Creative Commons Attribution license (http://creativecommons.org/licenses/by/4.0/). 